\title{
Correction to: Student representations and conceptions of ecological versus socialsciences in a conservation course
}

\author{
Amanda E. Sorensen ${ }^{1} \cdot$ Jeffrey Brown ${ }^{2} \cdot$ Ashley Alred $^{1} \cdot$ Joseph J. Fontaine ${ }^{3} \cdot$ Jenny M. Dauer $^{1}$ \\ Published online: 13 March 2020 \\ (C) AESS 2020
}

\section{Correction to: Journal of Environmental Studies and Sciences https://doi.org/10.1007/s13412-020-00594-w}

The article Student representations and conceptions of ecological versus socialsciences in a conservation course, written by Amanda E. Sorensen, Jeffrey Brown, Ashley Alred, Joseph J. Fontaine and Jenny M. Dauer, was originally published electronically on the publisher's internet portal (currently SpringerLink) on 13 February 2020 with open access. With the author(s)' decision to step back from Open Choice, the copyright of the article changed on March 2020 to (C) AESS 2020 and the article is forthwith distributed under the terms of copyright.

Publisher's note Springer Nature remains neutral with regard to jurisdictional claims in published maps and institutional affiliations.

The online version of the original article can be found at https://doi.org/ 10.1007/s13412-020-00594-w

Amanda E. Sorensen

amandaesorensen@gmail.com

1 School of Natural Resources, University of Nebraska-Lincoln, Lincoln, NE 68583-0984, USA

2 School of Environmental and Biological Sciences, RutgersUniversity, New Brunswick, NJ 08901-3502, USA

3 Nebraska Cooperative Fish \& Wildlife Research Unit, University ofNebraska-Lincoln, Lincoln, NE 68583-0984, USA 